\title{
A metric for customer lifetime value of credit card customers
}

Received (in revised form): 8th July, 2008

\section{Harsha Aeron}

is a doctoral student in IT and systems at the Indian Institute of Management, Lucknow, India. His main research interests are business intelligence, data mining applications, customer relationship management and customer lifetime value.

\section{Tarun Bhaskar}

is working as a lead scientist with GE Global Research in Bangalore, India. He received his PhD from the Indian Institute of Management, Calcutta in the area of Operations Research. His main research interests are customer relationship management, decision-making under uncertainty, soft computing techniques and combinatorial optimisation problems.

\section{Ramasubramanian Sundararajan}

works as a lead scientist with the Computing and Decision Sciences Lab in GE Global Research, India. He received his PhD from the Indian Institute of Management, Calcutta in the area of management information systems. His work concentrates on the application of predictive modelling and optimisation techniques to varied problems in engineering and management. His research interests are machine learning, soft computing and optimisation.

\section{Ashwani Kumar}

is presently an associate professor in IT and systems at the Indian Institute of Management, Lucknow. His current research interests are business intelligence, data mining and knowledge discovery, and computational intelligence and its applications in business. He received his PhD from the ABV-Indian Institute of Information Technology and Management, Gwalior, his MS from National University of Singapore, his MBA from University of Melbourne, Australia and his B Tech (EE) from the Indian Institute of Technology, Kanpur.

\section{Janakiraman Moorthy}

is Professor of Marketing at Pearl School of Business, and on leave from Indian Institute of Management, Lucknow. He specialises in advanced marketing research, new product development, customer value creation and market orientation of firms. His recent publications were in Journal of Database Marketing \& Customer Strategy Management and Marketing Science. His current work is focused on reviewing the methodologies for customer valuation and marketing productivity analysis. He received his PhD from Indian Institute of Management, Ahmedabad, India and was Global Research and Project Director of Institute for Customer Relationship Management, Atlanta, USA.

Keywords customer relationship management, customer lifetime value, credit card, financial services

Abstract Estimating customer lifetime value (CLV) is becoming increasingly important in order for firms to identify and invest on prospective profitable customers. A credit card issuer firm has to take several different decisions regarding a customer throughout her stay with the firm. CLV estimation can help a firm in making some of these crucial decisions. In this paper, we have presented a conceptual model for revenue from a credit card customer and have further presented a metric for CLV. This metric has been designed specifically for credit card customers. We have simulated different states of a customer to demonstrate how the proposed metric works.

Journal of Database Marketing \& Customer Strategy Management (2008) 15, 153-168. doi:10.1057/dbm.2008.13; published online 15 September 2008

FPM-33, Indian Institute of Management Off Sitapur Road Lucknow-226013, India e-mail: harsha.aeron@gmail. com

\section{INTRODUCTION}

Credit cards are replacing currency in many emerging markets and are also nearing saturation in developed economies such as the US. By providing a revolving credit facility, credit cards empower customers 
to manage their cash requirements with convenience for a fee. As the customers demanding credit are increasing, so are the firms that are ready to satisfy this demand, resulting in tough competition. There are many card-issuing banks and nonbank companies in the market. More than 90 per cent of the market-share is with less than 1 per cent of these units. ${ }^{1}$

The prevalence of tough competition in the industry and the relatively high costs of acquisition as compared to retention compel card issuers to be customer-centric and make the right decisions for the right customer at the right time. These decisions require customer information and predictions regarding the value of the customer from the card issuer's perspective. Customer lifetime value (CLV) is a metric that indicates the value of the customer.

A credit card firm has to take various decisions throughout the lifetime of its relationship with the customer, that is, from acquisition to attrition or default. The set of decisions starts with deciding which customers to acquire. As acquisition involves cost and there is a fixed budget assigned for it, a firm aims to select customers with high profit potential and low risk. Owing to the revolving nature of a credit card product, however, the relationship between profit and risk in a card is more complex than in a closed-end loan. Similar to other financial organisations, the card issuer bank would prefer customers to pay back the amount that they have borrowed using their card. It may not, however, want customers to pay back the entire amount in the first cycle itself. It may, instead, prefer them to 'revolve' and generate revenue for the bank. During the lifetime, the card issuer company needs to decide on the credit limit and price for each customer. At the retention stage, again, a firm has to decide whom to retain and how many resources to allocate for retention. These decisions can be guided by the CLV of the customer.

Estimating the CLV of a credit card customer can help a card issuer bank in taking the aforesaid decisions. First, at the time of acquisition, customers with high CLV scores can be given priority and accordingly the channel to acquire can be decided, that is a costly channel for highworth individuals and a cheaper channel for prospects with low CLV scores. Similarly, estimating CLV can help in taking decisions at the retention stage. The firm may aim to retain customers with high CLV scores and can accordingly decide on the cost of retention efforts. Researchers have recommended CLV as a metric for selecting customers, designing marketing programs and taking informed decisions in a structured framework. ${ }^{2-4}$ Customers selected on the basis of the CLV metric are more profitable as compared to those customers selected on the basis of other widely used CRM metrics such as previous-period customer revenue, past customer value, customer lifetime duration, etc. ${ }^{5}$

In this paper, we discuss the revenue model of a credit card and use this to propose a conceptual model that captures the CLV of a credit card customer. We use this conceptual model to build the CLV estimation process. We simulate different states of a credit card customer using the proposed metric to demonstrate how this metric captures different states of the customer lifetime. The rest of the paper is organised as follows. The second section presents a literature review of CLV metrics and their drawbacks with respect to the credit card domain. The third section talks about the revenue of a card issuer bank and the effect of customer behaviour and bank decisions on the revenue. The fourth section presents the proposed conceptual model, the fifth section presents the CLV metric for a credit card customer, the sixth section presents the simulation results and the seventh section presents the conclusion.

\section{LITERATURE REVIEW}

The literature related to calculating CLV for any financial product is scarce. To the best 
of our knowledge, there is no existing work that talks about the CLV of credit card customers. There are, however, a few papers that propose metrics for CLV in a general case, or for consumer goods. Since there might be a possibility of using some of these metrics (with some changes) for financial products, we review these works and analyse their applicability to credit card customers.

On the basis of a review of CLV metric papers, ${ }^{2,6}$ the metrics can be divided into two broad classes:

- Metrics calculating total value contributed by a particular customer or a segment of customers. This classification can further be sub-classified as metrics for individual customers and metrics for customer portfolio.

- Metrics calculating value contributed by a customer at the time of acquisition, retention or expansion

One set of metrics ${ }^{7-9}$ have calculated CLV for individual customers. Few metrics take into account past transactions and inactivity of the customer. ${ }^{8,9}$ The other set of CLV metrics are given for a cohort of customers. ${ }^{10-12}$ These help in analysing the effects of elements of marketing on the long-term value of the firms' customer base, in calculating profitability from a growing customer base and in giving a metric to gauge revenue from a cohort of customers at different relationship stages. A common drawback with these metrics is that the customer heterogeneity is not represented in the metrics.

The other set of CLV metrics is one in which value from customer acquisition, customer retention and customer expansion (cross-selling or margin) is calculated. ${ }^{13-15}$ In these metrics, either a component of CLV-like acquisition or retention is represented, or a link between two components is shown. The main drawback with them is that they cater to only a portion of CLV, and not to the CLV of a customer as a whole. Thus, the value of a customer, throughout her lifetime, is not captured. Besides the aforementioned drawbacks of each set of metrics, almost all the metrics are given for consumer products and not for services where customer acquisition and retention are in a meaningful context.

A few limitations of the above metrics restrict their use for credit card customers. These limitations are as follows:

- For a consumer product, revenue increases with number of transactions. For a credit card, a chunk of revenue accrues when a customer revolves. But in the case of credit cards, default risk by a customer increases if she revolves more. The risk of default is not incorporated in the metrics given above.

- As mentioned above, a customer affects revenue by her borrowing and repayment behaviour, as she uses the card for purchases or cash withdrawals, revolving or becoming delinquent. The variation in revenue is not modelled by the above metrics.

- Revenue collected from a card depends on the amount borrowed and the amount revolved. The amount, which can be borrowed in period $(t)$, gets affected by the amount borrowed and revolved in period $(t-1)$ because of the presence of credit limit. Thus, change in credit limit can affect revenue. The interaction is not depicted in the above metrics.

The specific properties of the credit card industry and the inability of current CLV metrics to appropriately capture these properties indicates that there is a need to develop a CLV metric for credit card customers. This paper addresses this need by presenting a conceptual model and CLV metric.

\section{REVENUE MODEL}

In a credit card transaction, five parties are commonly involved, that is, the customer, 
the customer's bank (the card issuer), the merchant, the merchant's bank and a card network company. A customer borrows from a merchant through her bank's credit card and pays the amount back to her bank. There are various types of cards in the market such as the secured card and the unsecured card and various services are provided on these cards such as credit availability, cash withdrawal and foreign transactions. For our study, we are considering unsecured credit cards and are concentrating only on credit availability, that is, taking credit on a card.

A credit card provides an open-ended revolving line of credit where a customer is allowed to borrow within a limit, even if she has balance outstanding from previous purchases. A credit card firm earns its revenue mainly from interest, late fees, transaction fees, annual membership fees and others. The credit card transaction flow model is shown in Figure 1.

At the time of acquiring the card, the customer's card features such as credit limit, interest rates and repayment cycle are decided and the card issuer may receive membership fees and annual fees. If the customer purchases something on the card, the firm earns revenue in terms of transaction fees, assuming that a transaction fee is levied on purchases. Once the bill is produced for the customer, she has to pay the amount back by the due date. A customer can pay back in different ways: she can pay back the full amount, she can pay back less than the full amount but more than or equal to the minimum amount due, or she can pay back less than the minimum amount due. The revenue earned is dependent on the customer's repayment behaviour. If she pays back everything, the bank earns nothing in terms of interest or late fees. If she pays back less than the full amount but more than or equal to the minimum, she is said to revolve. The credit card firm earns interest on the outstanding amount. If she pays back less than the minimum amount, she is said to become a delinquent customer and the firm earns revenue in terms of late fees and interest. A point to be noted is that though transaction fees, interest and late fees are all earned in a particular billing cycle, cash flow happens only when the customer pays back the entire outstanding amount or part of the amount. Therefore, in a particular billing cycle, the revenue gets accrued according to the customer's borrowing and payment behaviour. Cash flows are shown by solid lines, while accrued revenue is shown by dashed lines in Figure 1. If the customer stays delinquent for longer than certain billing cycles, she is termed a defaulter. For the outstanding amount, the credit card firm pays the cost of funds.

A customer can borrow no more than the credit limit decided by the bank. As a customer borrows more, her available limit reduces and her outstanding amount increases. Revenue is earned in transaction fees every time the credit card is used, and in case of repayment, revenue is earned if a customer revolves or becomes delinquent. The borrowing and repayment behaviour of a customer is also affected by her environment, which is based on her situation, for example, liquidity constraint, state of the economy (employment rate) or the bank's stimulus (credit limit increase). The card usage process is shown in Figure 2.

As a result of borrowing and repayment, a customer moves from one state to another. These states are inactive, transact, revolve, delinquent, default and attrite. A detailed definition of these states is given in the fourth section. Each state affects revenue in a different manner. For example, a customer in a revolve state contributes by paying interest, while a customer in a delinquent state contributes by paying late fees. Revenue is also affected by the bank's decision, as it may change interest rates, annual membership fees, etc. The bank can also use these card features as control levers 


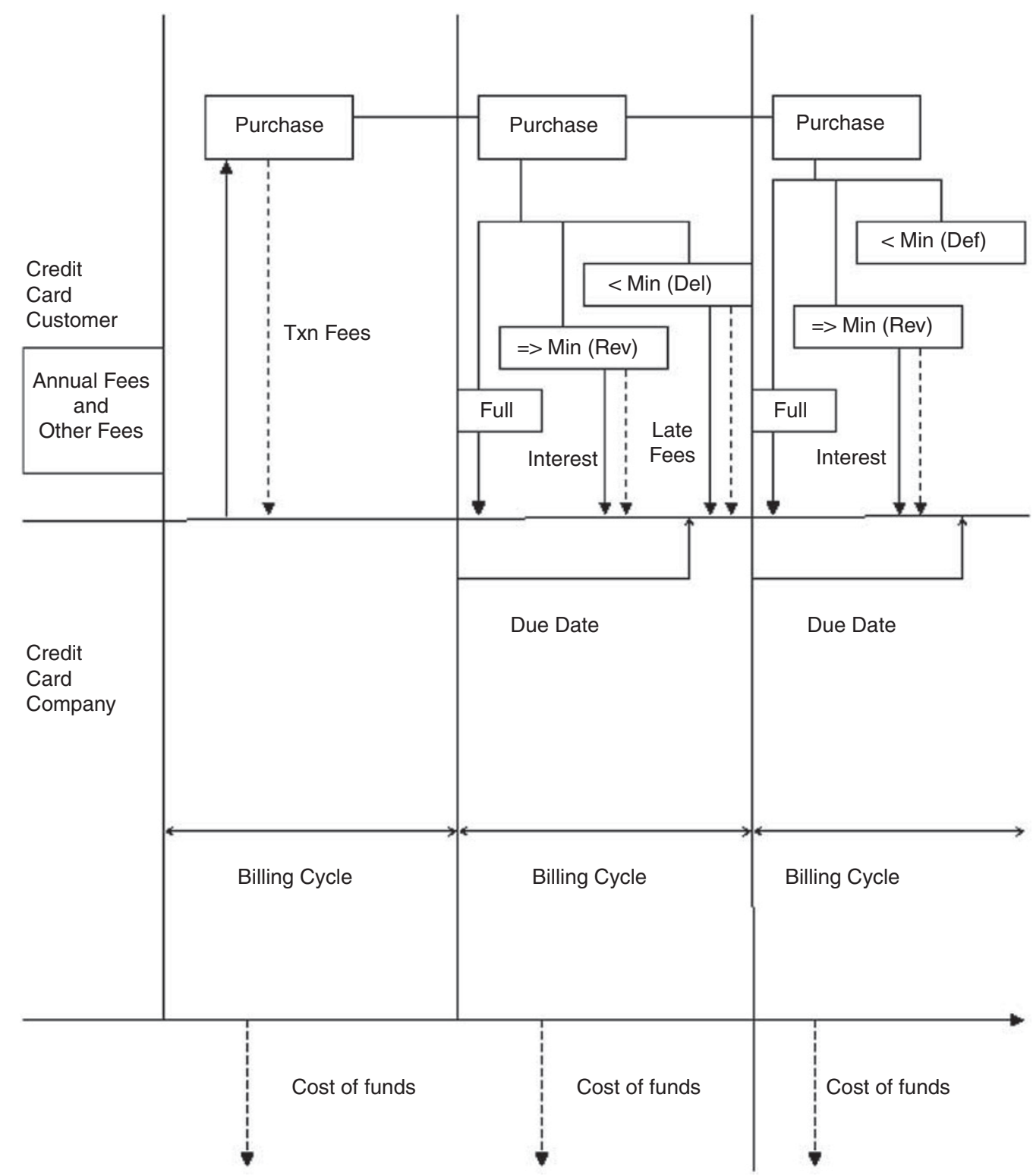

Figure 1: Credit card transaction flow model

or as stimuli to change a customer's behaviour. ${ }^{16,17}$ The revenue model of a bank is given in Figure 3.

As shown in above Figure 3, a customer affects revenue by being in different states regarding usage of the credit card and subsequent repayment. A card issuer bank can affect revenue inflow in two ways: first, by changing card features like interest rates, credit limit, annual fees, etc. Interest rates and annual fees affect revenue directly. Secondly, it can affect revenue inflow by using these card features to control the card usage behaviour of a customer. For example, an increase in credit limit to a customer may provoke her to borrow more and hence increase the chances that she will revolve. ${ }^{16,17}$ The very 


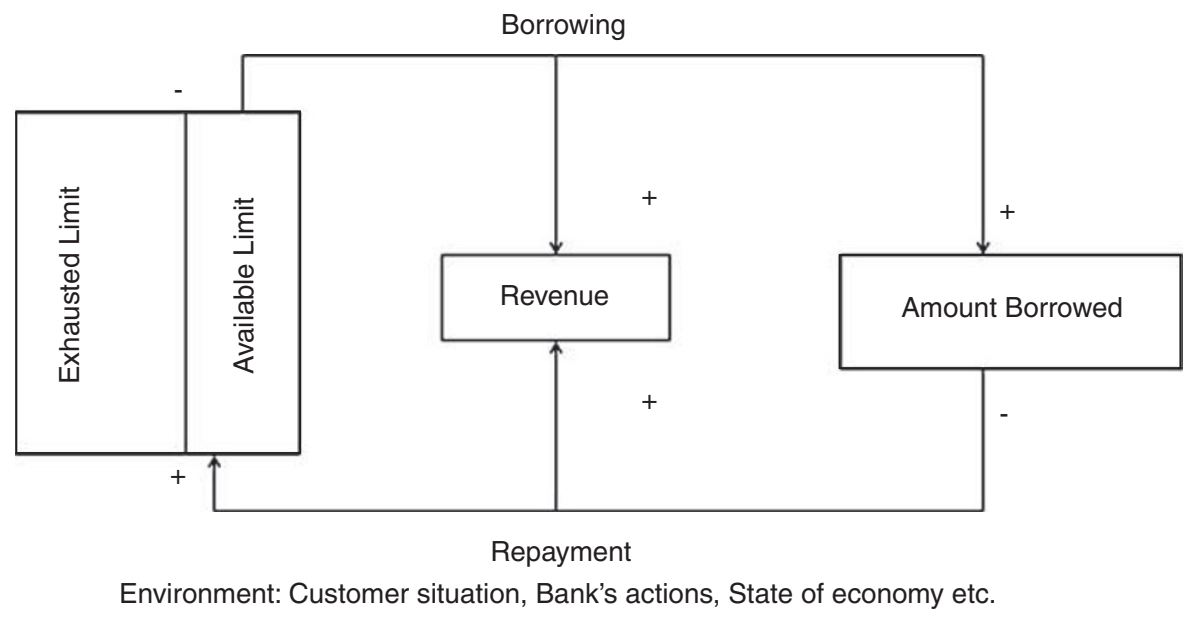

Figure 2: Card usage process

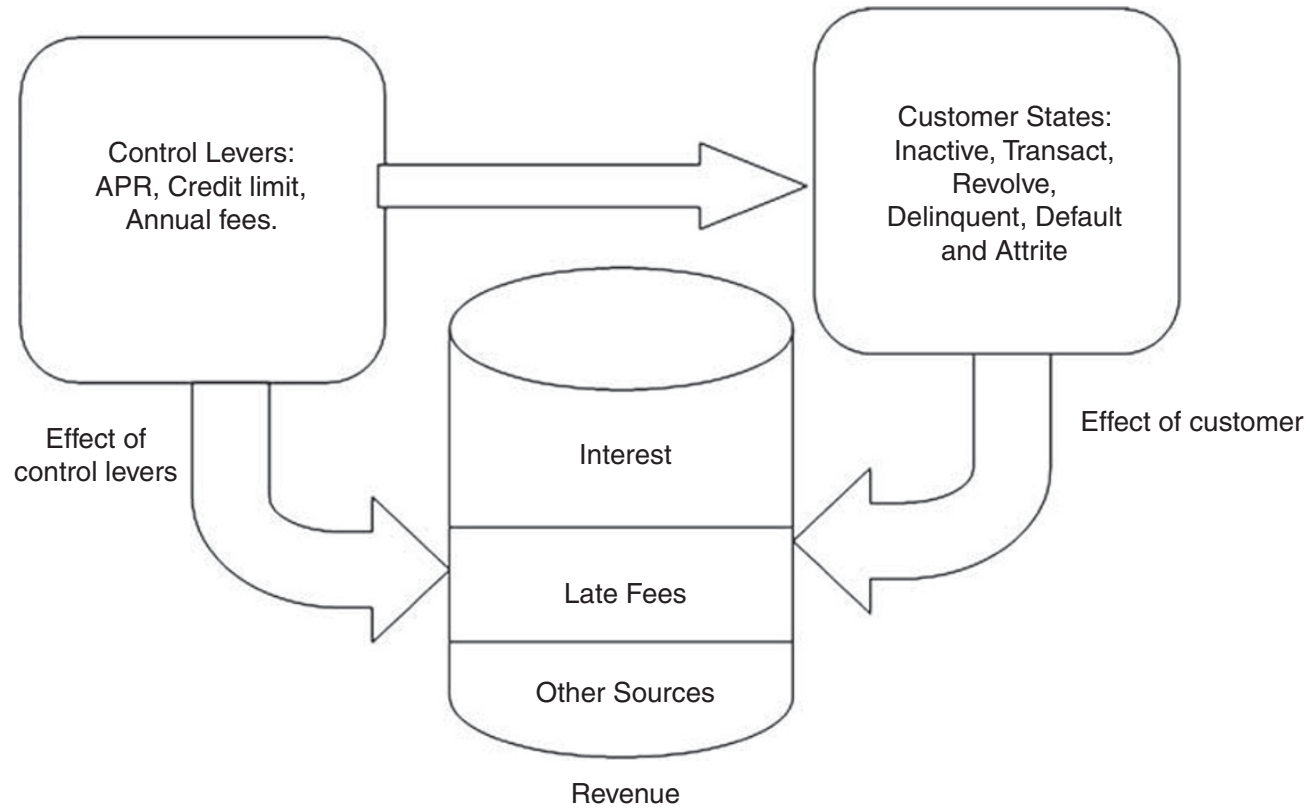

Figure 3: Revenue model

same action may, however, also increase the chance that she will borrow much more than she is able to repay and therefore she may go into a delinquent or default state.

\section{CONCEPTUAL MODEL FOR CLV}

The CLV metric proposed for a credit card customer is based on the conceptual model proposed in this section. The conceptual model simply depicts a customer's stay with the firm in terms of states defined in the earlier section. It further depicts the effect of customer behaviour and company decisions on the customer states and revenue. The states depend on the customer's borrowing and payment behaviour during a billing cycle and are 
defined below with the following assumptions:

(a) A state is defined at the end of a billing cycle according to borrowing and payment behaviour in that cycle.

(b) A customer can stay delinquent only for one billing cycle, after which, if she is still delinquent, she is considered to have defaulted. The model can be extended to cover further delinquency states (say 0-30 days, 31-60 days, 61-90 days, etc)

- we use only one delinquency state here for ease of explanation.

A customer's stay with the firm is divided into five states, namely inactive, transact, revolve, delinquent and default. For our paper we have defined the states as follows:

1 Inactive: If a customer has neither any outstanding from the last billing cycle nor has borrowed anything in the present cycle, then the customer is said to be in an inactive state in the present billing cycle. It means that a customer has neither borrowed, nor has revolved.Therefore, no revenue is earned from the customer in this state.

2 Transact: A transact state is defined by one of two conditions: first, a customer pays back the entire outstanding amount due on her credit card from the previous billing cycles or she borrows an amount in the present billing cycle. This outstanding amount may be the amount borrowed in the last cycle, plus interest accrued because of revolving in the last cycles or late fees as a result of delinquency in the last cycles. Although the interest and late fees are realised in the transact state, they are accrued in the revolve and delinquent state, respectively. Revenue accrues in the transact state in the form of transaction fees, but only if the customer borrows some money.

3 Revolve: A state in which a customer accrues interest on her credit card as a result of partial payment of the amount borrowed in the last billing cycle. The partial payment made by the customer should be more than the minimum payment prescribed by the credit card company. The interest accrued in the revolve state may be realised in the next revolve state or transact state. It is also possible that interest may not be realised if the customer defaults. A customer may also borrow more money by making further transactions while in a revolve state, as long as the value of these transactions is within the available credit limit.

4 Delinquent:A state in which a customer accrues late fees as a result of insufficient or nonpayment of an amount borrowed. The late fees accrued in this state may be realised in the next transact state in which the customer pays back all of the outstanding amount or may not be collected if the customer defaults.

5 Default: A state in which a delinquent customer fails to pay the required outstanding amount - a loss-making state.

As a result of customer payment behaviour, a state of attrition can also result, in which she pays back the entire outstanding amount and then switches to another bank. Attrition results in loss of potential revenue through future transactions. Sometimes, a prolonged inactive state can also be interpreted as attrition.

\section{State change}

A customer's stay with the company can be broken down in terms of states: inactive, transact, revolve, delinquent, default and attrition. As mentioned above, a credit card firm can affect customer borrowing and payment behaviour by altering card features such as interest rates and credit limit, which in turn affects revenue. But a bank's decision can also affect revenue generation directly by changing card features. For example, a change in interest rates changes revenue generations. The above discussion is presented in the form of a conceptual model in Figure 4. 


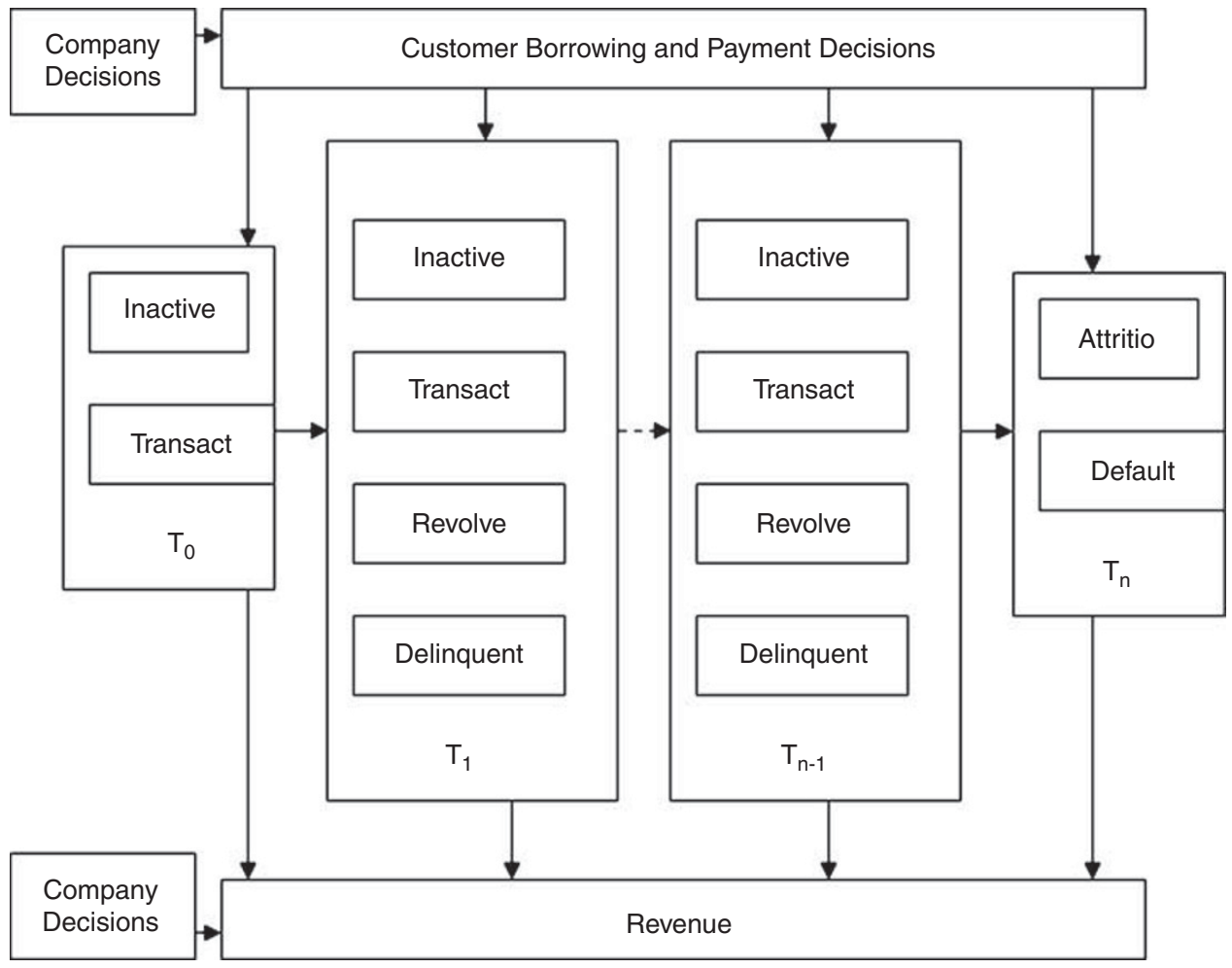

Figure 4: The conceptual model

Once a customer has been acquired, she can start her stay with the firm with either an inactive or transact state. The inactive state occurs if the customer carries out no activity for the first billing cycle, and the transact state occurs if she makes any transaction(s) with the card. Once she becomes a transactor, she can further change states on the basis of her payment behaviour. In the next state, a transactor can become a revolver or a delinquent customer or can remain a transactor. On the basis of her payment behaviour, a revolver can assume the next state as either remain a revolver, become a delinquent customer or become a transactor. And finally, a delinquent customer can change her state to a transactor, a revolver or a default customer. The transact state is a state in which a customer pays back the full outstanding amount and therefore all the states will eventually end up as transact or default. The case of attrition is a special case of transact state in which a customer pays back everything and then switches to another firm. Therefore, a customer's stay with the firm either ends with default or with attrition. The above discussion is presented in Figures 5 and 6.

Figures 5 and 6 show two state-change sequences (shown by dotted and solid lines) out of many possible scenarios. $\mathrm{T} 0_{-}$and $\mathrm{TO}_{+}$are the time periods just before and after acquiring a customer, respectively. Figure 6 shows all the possibilities of state change from one time period to another. Crosses denote a nonpossibility while a star denotes a possibility. A point to be noted is that default and attrite states are the last states in any sequence of states. A hypothetical sequence of states is shown below. In the situation depicted in Figure 7, a customer is leaving the company by default. Here, each bar represents a state, and 


\begin{tabular}{|c|c|c|c|c|c|c|c|c|}
\hline & & \multicolumn{7}{|c|}{ States } \\
\hline & & Acquire & Inactive & Transact & Revolve & Delinquent & Default & Attrite \\
\hline \multirow{9}{*}{ 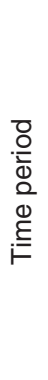 } & T0. & $\bar{x}$ & & & & & & \\
\hline & $\mathrm{TO}_{+}$ & & 4 & $\cdots$ & & & & \\
\hline & T1 & & & & & $\therefore:=\Rightarrow$ & & \\
\hline & T2 & & $<$ & & & & & \\
\hline & T3 & & & & & & & \\
\hline & $\mathrm{T} 4$ & & $4 \cdots$ & 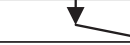 & & & & \\
\hline & T5 & & t. & & & & & \\
\hline & T6 & & & $\rightarrow \infty$ & & & & \\
\hline & $\mathrm{T} 7$ & & & & & & $\cdots$ & $\rightarrow$ \\
\hline
\end{tabular}

Figure 5: State change

\begin{tabular}{|c|c|c|c|c|c|c|c|c|}
\hline & & \multicolumn{7}{|c|}{ States in Time Period 2} \\
\hline & & Acquire & Inactive & Transact & Revolve & Delinquent & Default & Attrite \\
\hline \multirow{7}{*}{ 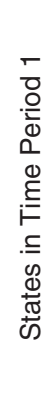 } & Acquire & $\mathrm{X}$ & $*$ & $*$ & $\mathrm{X}$ & $\mathrm{X}$ & $\mathrm{X}$ & $\mathrm{X}$ \\
\hline & Inactive & $\mathrm{X}$ & $*$ & $*$ & $\mathrm{x}$ & $\mathrm{X}$ & $\mathrm{X}$ & $*$ \\
\hline & Transact & $\mathrm{X}$ & $*$ & $*$ & $*$ & $*$ & $\mathrm{X}$ & $*$ \\
\hline & Revolve & $X$ & $X$ & $*$ & $*$ & $*$ & $X$ & $X$ \\
\hline & Delinquent & $\mathrm{X}$ & $\mathrm{X}$ & $*$ & $*$ & $\mathrm{X}$ & $*$ & $\mathrm{x}$ \\
\hline & Default & $X$ & $X$ & $X$ & $\mathrm{x}$ & $\mathrm{X}$ & $X$ & $\mathrm{X}$ \\
\hline & Attrite & $X$ & $X$ & $X$ & $X$ & $X$ & $X$ & $X$ \\
\hline
\end{tabular}

Figure 6: State change possibilities

height represents the amount outstanding at that state (other then inactive state).

\section{THE CLV METRIC}

The value contributed by a credit card customer depends on the state of the customer in a particular time period $(t)$. The contributed value $(\mathrm{CV})$ from a particular state is based on the following assumptions:

1 A card issuer bank incurs maintenance cost and cost of funds.

2 The value of a state is the value accrued in that state. For example, a late fee from a delinquent state is accrued as soon as a customer becomes delinquent, but is earned when she pays back.
3 Late fees incorporate the interest amount charged in the delinquency period.

4 No interest is charged on the new borrowed amount for one cycle, even if the customer has not paid back the old amount completely.

5 A transaction fee is present and fixed (as a percentage of the borrowed amount) for all purchases.

To estimate accrued revenue from each billing cycle, we have to predict two sets of parameters for each state. The parameters are probabilities of different states to occur and the amount associated with these states. Thus, revenue from a state at time period $(t)$ can be placed proportional to the 


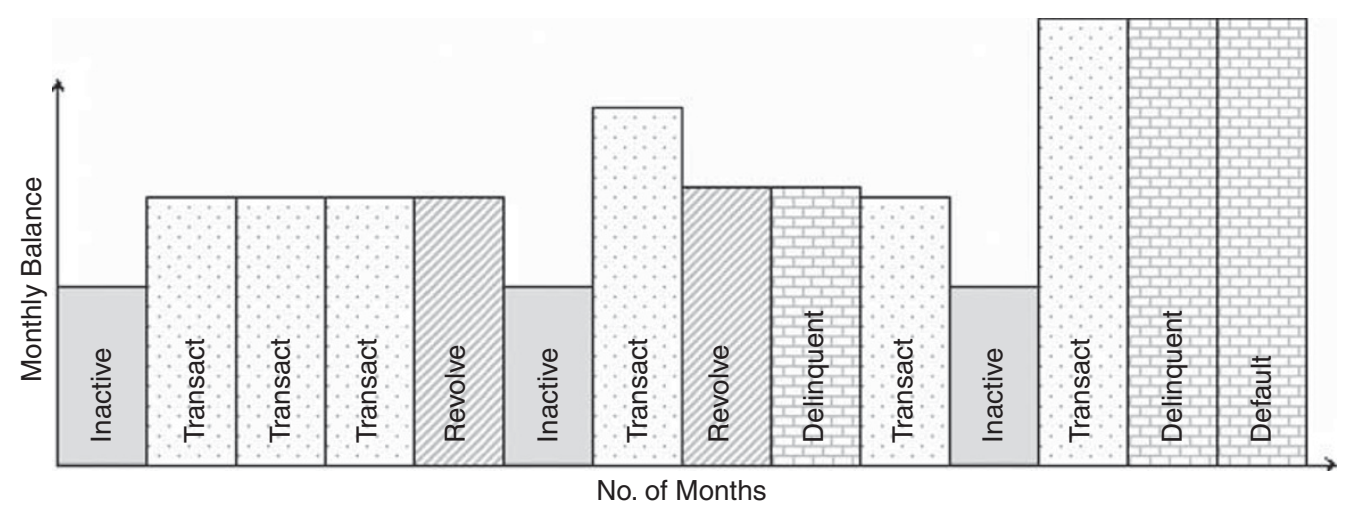

Figure 7: Customer states

probability of a state to occur and amount associated with that state.

$$
\text { Re venue }{ }_{t}^{\text {State }}=\text { Pr obability } y_{t}^{\text {State }} * \text { Amount }_{t}^{\text {State }}
$$

The CV for each state can be calculated with the above formula. The transact state occurs either due to borrowing or due to payment of the entire outstanding amount from the previous cycle. Earnings, however, take place because of borrowing only. Revenue from the borrowing portion of the transact state can be represented as $a \rho_{t}^{B o r} A_{t}^{B o r}$ where $a$ is the transaction fees in percentage and $\rho_{t}^{B o r}$ and $A_{t}^{B o r}$ are the probability and amount to borrow, respectively. Revenue from the revolve state is the interest percentage on the amount revolved and can be depicted as $i \rho_{t}^{R e v} A_{t}^{R e v}$, where $i$ is the interest percentage, $\rho_{t}^{\text {Rev }}$ is the probability to revolve and $A_{t}^{R e v}$ is the amount revolved. Revenue from the delinquent state is the revenue from late fees and can be depicted by $l \rho_{t}^{D e l} A_{t}^{D e l}$ where $l$ is the late fees percentage, $\rho_{t}^{D e l}$ is the probability to become delinquent and $A_{t}^{D e l}$ is the amount associated with the delinquent state.

There is also a constant maintenance cost (depicted as C), which is present for each state. A bank incurs cost of funds for outstanding amounts. The cost of funds can be depicted as $b\left(\rho_{t}^{B o r} A_{t}^{B o r}+\rho_{t}^{R e v} A_{t}^{R e v}+\right.$ $\left.\rho_{t}^{\text {Del }} A_{t}^{D e l}\right)$ where $b$ is the hurdle rate. Note that a customer may borrow money even when she is revolving or is in a delinquent state. Therefore, in a particular state, revenue may come from borrowing and revolve or from borrowing and delinquency, as revolve and delinquency are exclusive states. Loss due to default is depicted by $\rho_{t}^{D e f} A_{t-1}^{D e l}$ where $\rho_{t}^{D e f}$ is the probability to default and $A_{t-1}^{D e l}$ is the delinquent amount in the last time period and the amount associated with the default stage. The amount defaulted is the same as amount associated with delinquent stage in the last billing cycle.

The CV of a credit card customer in time period $(t)$ can be placed as revenue coming from the state in that time period minus the costs incurred in that state. Revenue can come from different states, namely transact, revolve and delinquent, and losses can occur due to a default state. Thus, $\mathrm{CV}$ due to a state in time period $(t)$ can be placed as revenue from three states, that is, transact, revolve and delinquent minus the costs and losses mainly in terms of cost of maintenance, cost of funds and loss due to default. In the formula, revenue from all the states are added up, though revenue will come either from borrowing, revolving, delinquency, borrowing and revolving together or borrowing and delinquency 
together. The discrepancy is taken care of by probabilities in the formula, as probability to revolve and delinquent are exclusive. Similarly, probability to default is exclusive to all other probabilities. Thus, CV at the end of cycle $(t)$ can be given as

$$
\begin{aligned}
& \text { Contributed Value of a credit card customer } \\
&=\text { Revenue from revolving period } \\
&+ \text { Revenue from delinquency period } \\
&+ \text { Revenue from borrowings }) \\
&- \text { Cost of maintenance + Cost of funds } \\
&+ \text { loss due to default } \\
& C V_{t}=\left(a \rho_{t}^{\text {Bor }} A_{t}^{\text {Bor }}+i \rho_{t}^{\mathrm{Rev}} A_{t}^{\mathrm{Rev}}+l \rho_{t}^{\mathrm{Del}} A_{t}^{\text {Del }}\right) \\
&-\left(C+b\left(\rho_{t}^{B o r} A_{t}^{\text {Bor }}+\rho_{t}^{\mathrm{Rev}} A_{t}^{\mathrm{Rev}}+\rho_{t}^{\text {Del }} A_{t}^{\text {Del }}\right)\right. \\
&\left.+\rho_{t}^{\text {Def }}-A_{t-1}^{\text {Del }}\right)
\end{aligned}
$$

or

$$
\begin{aligned}
C V_{t}= & \left((a-b) \rho_{t}^{\text {Bor }} A_{t}^{B o r}+(i-b) \rho_{t}^{\mathrm{Re} v} A_{t}^{\mathrm{Re} v}\right. \\
& +(l-b) \rho_{t}^{D e l} A_{t}^{D e l}-\rho_{t}^{D e f} A_{t-1}^{D e l}-C
\end{aligned}
$$

There exists a relationship between transacting amount, revolving amount and amount in a delinquency state. The revolving amount in period $(t)$ will always be a percentage of borrowing amount, revolving amount and delinquent amount in period $(t-1)$ that is

$$
A_{t}^{\mathrm{Re} v}=m_{t}\left(A_{t-1}^{\mathrm{Re} v}+A_{t-1}^{\text {Bor }}+A_{t-1}^{\mathrm{Del}}\right)
$$

where $m_{t}$ is the percentage value. There exist upper and lower bounds on the value of $m_{t}$. The upper bound is set by minimum payment set by the bank, as an amount above a certain percentage will make a customer delinquent. The lower bound is zero, as zero amount revolved means no revolve. The value of $m_{t}$ may vary for each period. Similarly, a delinquent amount in period $(t)$ will always be a percentage of the borrowing amount and the revolving amount in period $(t-1)$. Therefore,

$$
A_{t}^{\text {Del }}=n_{t}\left(A_{t-1}^{\mathrm{Re} v}+A_{t-1}^{\text {Bor }}\right)
$$

where $n_{t}$ is the percentage value. The lower bound of $n_{t}$ is the same as upper bound of $m_{t}$, as payment should be less than the minimum payment to term a customer a delinquent customer. The upper bound of $n_{t}$ is 100 per cent. CV equation can be written as

$$
\begin{aligned}
C V_{t}= & (a-b) \rho_{t}^{\text {Bor }} A_{t}^{\text {Bor }} \\
& +(i-b) m_{t} \rho_{t}^{\mathrm{Re} v}\left(A_{t-1}^{\mathrm{Re} v}+A_{t-1}^{\text {Bor }}+A_{t-1}^{\text {Del }}\right) \\
& +(l-b) n_{t} \rho_{t}^{\text {Del }}\left(A_{t-1}^{\mathrm{Re} v}+A_{t-1}^{\text {Bor }}\right) \\
& -\rho_{t}^{\text {Def }} A_{t-1}^{\text {Del }}-C
\end{aligned}
$$

Rewriting the above equation, we get

$$
\begin{aligned}
C V_{t}= & (a-b) \rho_{t}^{B o r} A_{t}^{B o r}+(i-b) m_{t} \rho_{t}^{\mathrm{Re} v} \\
& \left.+(l-b) n_{t} \rho_{t}^{D e l}\right) A_{t-1}^{\mathrm{Rev}}+\left((i-b) m_{t} \rho_{t}^{\mathrm{Re} v}\right. \\
& \left.+(l-b) n_{t} \rho_{t}^{D e l}\right) A_{t-1}^{\text {Bor }} \\
& +\left((i-b) m_{t} \rho_{t}^{D e l}-\rho_{t}^{D e f}\right) A_{t-1}^{D e l}-C
\end{aligned}
$$

With the help of equations 4 and 5, the terms of $A_{t-1}^{R e v}$ and $A_{t-1}^{D e l}$ can be expressed in terms of borrowing amount through an iterative process, which may end at the amount borrowed first.

The proposed metric is similar to the net profit part of a basic structural metric of CLV given in Jain and Singh. ${ }^{2}$ CLV can be formulated as

$$
\mathrm{CLV}=\sum_{t=1}^{T} \mathrm{CV}_{t} /(1+d)^{t}
$$

The above metric is a summation of $\mathrm{CV}$ from the point of acquisition to the time window we want to calculate CLV. 
The above CLV metric does not take into account opportunity loss due to attrition, as it is the summation of $\mathrm{CV}$ from the start to the end of the prediction window. But, as attrition will affect the future revenue inflow, CLV metric can be given as

$$
\mathrm{CLV}=\sum_{t=1}^{T} \mathrm{CV}_{t} /(1+d)^{t}-\text { Attritionloss }
$$

where value of attrition loss is summed CV from the point where attrition has taken place. If the customer's lifetime is $T$, and has business with the company, there is no loss. But if she leaves before $T$, say $T-t$ th period, then there is opportunity loss due to losing future revenue.

The advantages of proposed $\mathrm{CV}$ and subsequently CLV metric are

1 It is represented in the form of transaction amount, probability of existence of a state at time $(t)$ and the percentages of amount revolved. These values can be taken from a data set and can be predicted. One way of estimating probability of transition from one state to another is through Markov Model. ${ }^{18}$ The amount associated with transaction, revolve and delinquency may be predicted with regression.

2 This helps a bank in observing the following:

- How parameters such as probabilities and amount associated with each state depend on customer characteristics.

- How parameters change with change in card features, for example, interest rates, credit limit, etc.

- How much revenue is collected from different sets of parameters.

- What the effect is on parameters of environment conditions like employment rates.

The above observations can help in making the following decisions:

- As customer characteristics can be related to revenue, more informed decisions regarding acquisition and retention can be taken. The card issuer could decide whom to acquire and retain by comparing the costs related to acquisition or retention with the projected benefits (in terms of CLV or its components).

- Various decisions regarding personalisation of the card features can be made using this metric. For example, the card issuer can decide on different interest rates, credit limit, etc for different customers by examining the impact of a change in these parameters on the components of CLV. For instance, an increase in credit limit may impact the borrowing behaviour of one customer without any adverse impact on repayment behaviour. The very same increase, however, may cause another customer to become delinquent. Thus, by examining these effects, the card issuer can decide whom to give a credit limit increase (and for what amount) such that its revenue is increased without substantially greater risk.

- The proposed metric can help a bank in deciding its customer portfolio, as it can decide on the number of transactors and revolvers in its portfolio.

- By observing the transition of customers to delinquent (and default) state, the bank can put in place appropriate steps to ensure that its losses are minimised. From a regulatory and hedging standpoint, these transition probabilities could also allow the bank to estimate its economic capital allocation.

The limitations of the proposed metric are as follows

1 The contributing value of different portions may be dependent on customer characteristics and customer environment. For example, revolving behaviour may change with education or with employment conditions. This relationship is not depicted. 
2 The proposed CLV metric does not take into account cost of acquisition, cost of retention, word-of-mouth effect, etc.

3 The present metric has taken a few simplistic assumptions, such as the presence of one delinquency state, the constancy of transaction fees for all purchases, no interest on the amount borrowed in a revolve period, etc.

4 The metric is based on accrued revenue rather than on real cash flows and as a result the estimated CLV will be different from the real CLV value because of the discounting factor.

\section{SIMULATION}

We have simulated the equation 6 to capture different states. The values of different probabilities and amounts are derived from a subset of a credit card portfolio. For confidentiality reasons, the details of the business cannot be provided here. The values of interest, cost of funds, late fees and transaction fees are taken on the basis of data for that portfolio. For the purpose of simulation, we have assumed maintenance cost to be zero. The variables given in the data are purchase amount in a month, amount outstanding in a month, revolve flag, delinquent flag and default flag.

To calculate $\rho^{\text {Bor }}$, all the incidents of borrowing are counted in a certain number of months and then divided by the total number of months and total number of customers. The value of $\rho^{\text {Bor }}$ is 0.12 . To calculate values of $\rho^{R e v}, \rho^{D e l}$ and $\rho^{D e f}$, a transition matrix is built on the basis of actual observed state transitions in the data. All the customer states in the data set are marked as inactive, transact, revolve, delinquent and default, according to our definitions. All the records conforming to our definitions are kept, while others are deleted. All the state changes from period $(t)$ to period $(t+1)$ are counted for the whole database and then normalised by the row total to get probability values. The values of the matrix are given below.

\begin{tabular}{lllll}
\hline & $T_{t+1}$ & $R_{t+1}$ & $D e l_{t+1}$ & $D e f_{t+1}$ \\
\hline$T_{t}$ & 0.93 & 0.06 & 0.01 & 0 \\
$R_{t}$ & 0.48 & 0.50 & 0.02 & 0 \\
Del $t$ & 0.82 & 0.1 & 0 & 0.08 \\
\hline
\end{tabular}

The matrix denotes the probability of becoming a transactor, revolver or delinquent customer. According to our definitions, there are a few state transitions that are not possible. For example, a customer cannot move from a transact or revolve state to a default state. Similarly, a customer cannot remain delinquent for more than one time period, as depicted in Figure 6.

The amount borrowed and amount revolved are simulated using a Beta distribution. This distribution is justified in cases where there is an upper and lower bound of values. The amount borrowed is simulated, for instance, as a percentage of the available credit limit in a given cycle. In the case of percentage of amount revolved, the upper limit is 95 per cent of the outstanding balance ( 5 per cent being the minimum due) and the lower limit is approximately zero. The parameters of these distributions are determined using Crystal Ball software.

\section{Simulation results}

The simulation is performed in MATLAB to demonstrate the ability of the proposed metric in capturing different customer states. The borrowing and payment behaviour is simulated for 100 time periods and cumulative $\mathrm{CV}$ is drawn. The different states are captured in the CV graphs and are explained below.

\section{State 1. Transact}

Figure 8 shows the cumulative CV curve of a typical transactor, or a person who transacts most of the time with few revolve cycles. 
Most of the revenue collected from the customers is in terms of transaction fees depicted as small step. There are a few cycles where interest income is earned as well; these are depicted by relatively big steps around period 40 and 75 . As a result of prominent transaction behaviour, the total CV in 100 time periods is around 50.

\section{State 2. Inactive customers}

Figures 9 and 10 show a typical inactive customer, depicted by a flat line between 0 and 60 time periods in the first graph and between 50 and 80 time periods in the second. Because of inactivity, the total $\mathrm{CV}$ is less in both cases and revenue collected is

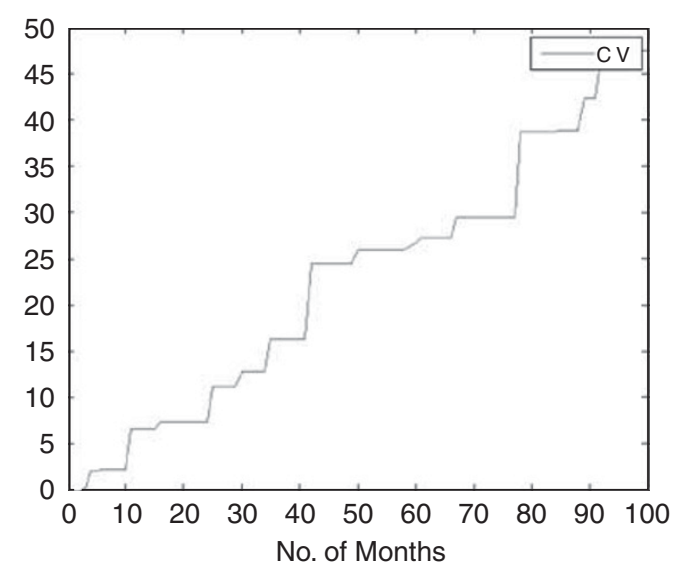

Figure 8: Simulation of a common customer behaviour

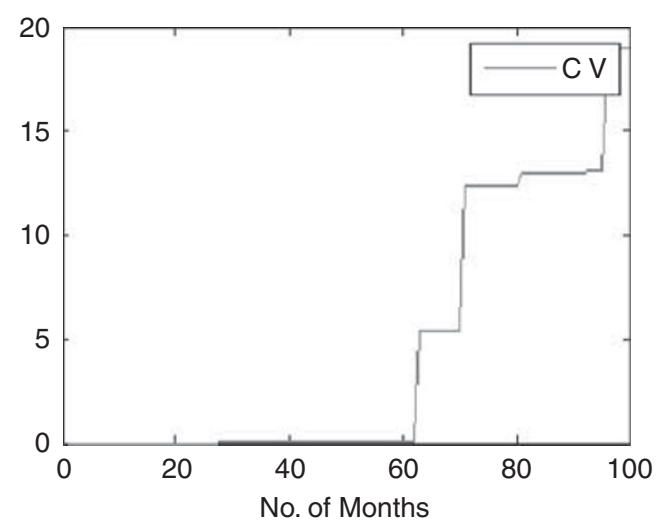

Figure 9: Simulated inactive behaviour 1 mainly because of a few revolving cycles in both cases. Therefore, we can say that low activity results in lower CLV.

\section{State 3. Revolve}

Figures 11 and 12 depict typical revolve behaviour. In the first graph, the customer is revolving at the end of her tenure, as is shown by a steep continuous rise of $\mathrm{CV}$ curve, while in the second curve, the customer revolves consecutively a few times at around the 20th month. As a result of revolve behaviour, there is a steep rise in revenue collected in both cases.

\section{State 4. Delinquent}

Figure 13 shows a delinquent customer. The customer becomes delinquent around month 20. As a result, CV curve rises sharply because revenue is earned in terms

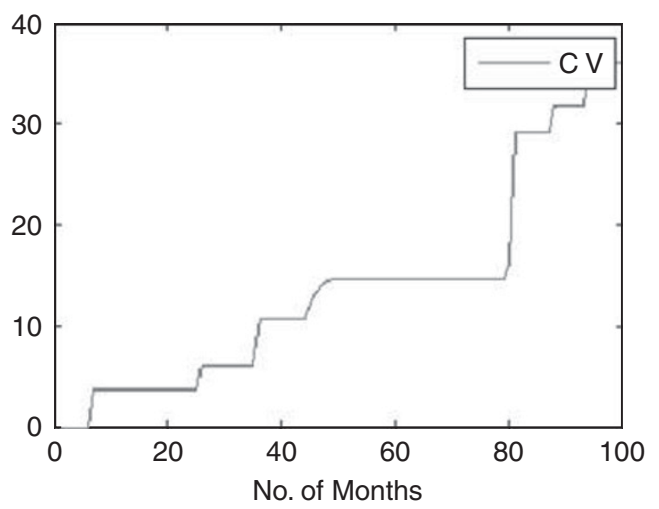

Figure 10: Simulated inactive behaviour 2

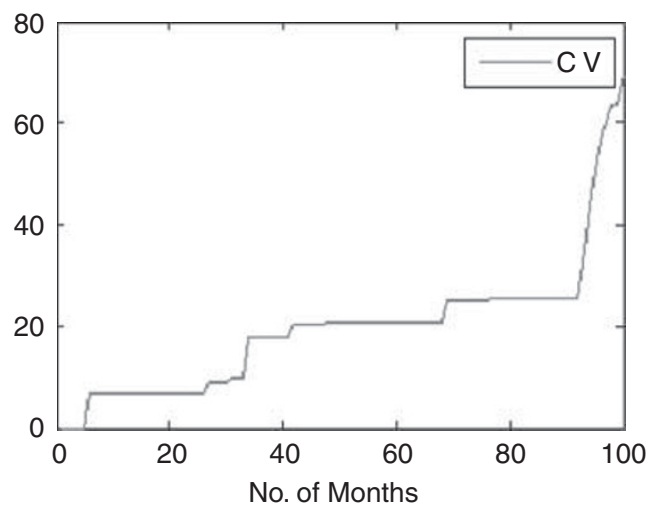

Figure 11: Simulated revolving customer behaviour 1 


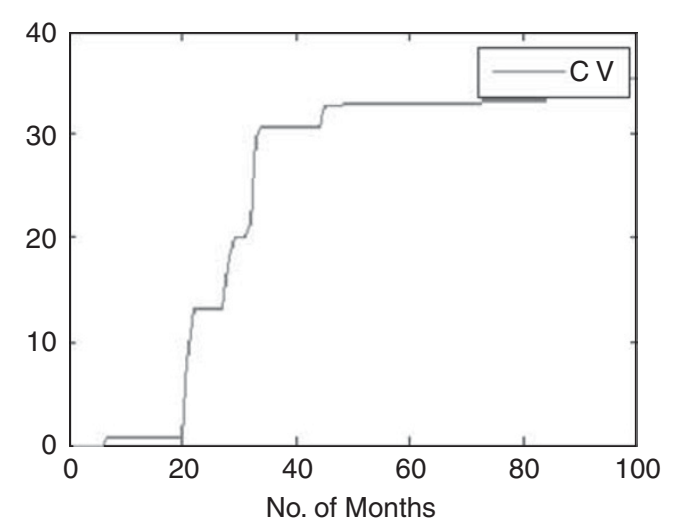

Figure 12: Simulated revolving customer behaviour 2

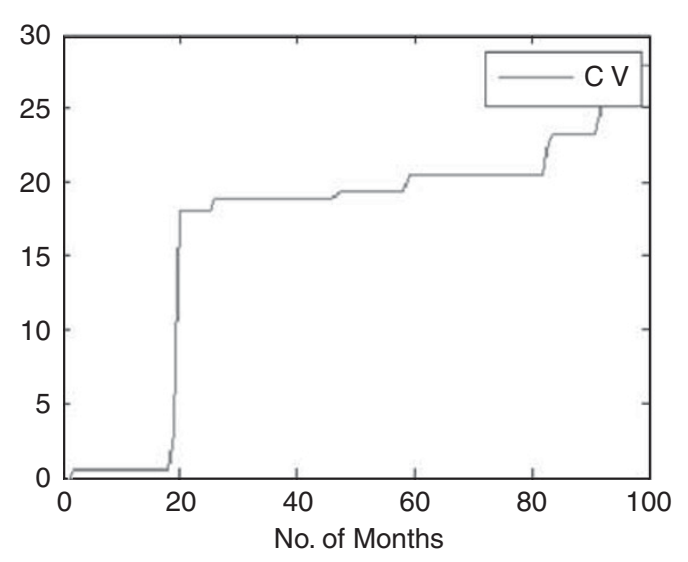

Figure 13: Simulated delinquent customer behaviour

of late fees, which is much higher than interest income and transaction fees. For most of the later time period, she remains inactive or transacts once in a while, as a result of which total $\mathrm{CV}$ does not increase much in later periods. A drawback of our simulation is that we were not able to capture the default state, as very few cases of default are present in the data set.

\section{CONCLUSION}

CLV is important for credit card firms in taking various decisions, from acquisition to retention of customers. In this paper, we have proposed a new CLV metric to model revenue from a credit card customer. The metric is based on a conceptual model that divides a customer's relationship (with respect to her card account) into different states. The revenue and costs from each state are summed to arrive at the CLV. Customer borrowing and payment behaviour is simulated to show that this metric is able to capture almost all states.

The biggest advantage of the proposed metric is that it is represented as a function of components that can be estimated from historical data and analysed both individually and collectively to get an idea of cardholder behaviour. For instance, the transaction amount, probability of existence in a state at time $(t)$ and the percentage of amount revolved are values that can be estimated from the available data. With the help of the metric, observations regarding customer behaviour can be made which can help a bank in making various decisions regarding acquisition, retention and personalisation of cards.

The metric proposed in the paper is a simple metric based on only a few assumptions. As a result, all the complexities of the credit card industry are not incorporated. Further research can be done by incorporating these complexities. Other research directions can be incorporating different costs such as cost of acquisition, validating the affect of company decisions on customer borrowing and payment decisions, and incorporating more variables in the metric, such as customer characteristics (age, gender and education) and customer environment (employment).

\section{Acknowledgments}

This work was done when the first author was working with Computing and Decision Sciences Lab in GE Global Research, Bangalore.

\section{References}

1 Min, I. and Kim, J. (2003) 'Modeling credit card borrowing: A comparison of type I and type II tobit approaches', Southern Economic Journal, Vol. 70, No. 1, pp. $128-143$.

2 Jain, D. and Singh, S. S. (2002) 'Customer lifetime value research in marketing: A review and future 
directions', Journal of Interactive Marketing, Vol. 16, No. 2, pp. 34-46.

3 Reinartz, W. J. and Kumar, V. (2003) 'The impact of customer relationship characteristics on profitable lifetime duration', Journal of Marketing, Vol. 67, pp. 77-99.

4 Rust, R. T., Zeithaml, V. A. and Lemon, K. N. (2004) 'Return on marketing: Using customer equity to focus marketing strategy', Journal of Marketing, Vol. 68, pp. 23-53.

5 Venkatesan, R. and Kumar, V. (2004) 'A customer lifetime value framework for customer selection and resource allocation strategy', Journal of Marketing, Vol. 68, pp. 106-125.

6 Gupta, S., Hanssens, D., Hardie, B., Kahn, W., Kumar, V., Lin, N., Ravishankar, N. and Sriram, S. (2006) 'Modelling customer lifetime value', Journal of Service Research, Vol. 9, No. 2, pp. 139-155.

7 Berger, P. D. and Nasr, N. I. (1998) 'Customer lifetime value: Marketing models and applications', Journal of Interactive Marketing, Vol. 12, No. 1, pp. 17-29.

8 Schmittlein, D. C., Morrison, D. G. and Colombo, R. (1987) 'Counting your customers: Who are they and what will they do next', Management Science, Vol. 33, pp. 1-24.

9 Fader, P. S., Hardie, B. and Berger, P. D. (2004) 'Customer-base analysis with discrete-time transaction data', Unpublished working paper. (Cited in Gupta S. et al., 2006).

10 Blattberg, R. C. and Thomas, J. S. (1997) 'Dynamic pricing strategies to maximize customer equity',
Unpublished manuscript, Northwestern University, Evanston, IL.1997. (Cited in Jain and Singh, 2002).

11 Blattberg, R. C. and Thomas, J. S. (2000) 'Valuing, analyzing and managing the marketing function using customer equity principles', Unpublished manuscript, Northwestern University, Evanston, IL. (Cited in Jain and Singh, 2002).

12 Johnson, M. D. and Selnes, F. (2004) 'Customer portfolio management: Towards a dynamic theory of exchange relationships', Journal of Marketing, Vol. 68, pp. 1-17.

13 Blattberg, R. C. and Deighton, J. (1996) 'Manage marketing by the customer equity test', Harvard Business Review, Vol. 74, No. 4, pp. 136-144.

14 Hansotia, B. and Wang, P. (1997) 'Analytical challenges in customer acquisition', Journal of Direct Marketing, Vol. 11, No. 2, pp. 7-19.

15 Pfeifer, P. and Carraway, R. (2000) 'Modeling customer relationships as Markov chains', Journal of Interactive Marketing, Vol. 14, No. 2, pp. 43-55.

16 Soman, D. and Cheema, A. (2002) 'The effect of credit on spending decisions: The role of the credit limit and credibility', Marketing Science, Vol. 21, No. 1, pp. 32-53.

17 Stanghellini, E. (2003) 'Monitoring the behaviour of credit card holders with graphical chain models', Journal of Business \& Accounting, Vol. 30, No. 9 and 10, pp. 1423-1435.

18 Till, J. R. and Hand, D. J. (2003) 'Behavioral models of credit card usage', Journal of Applied Statistics, Vol. 30, No. 10, pp. 1201-1220. 